\title{
An Experimental Study of a Novel Integrated Desiccant Air Conditioning System for Building Applications
}

\author{
Theo Elmer ${ }^{a^{*}}$, Mark Worall ${ }^{a}$, Shenyi Wu ${ }^{a}$ and Saffa Riffat ${ }^{a}$ \\ ${ }^{a}$ Architecture, Energy and Environment Research Group, The University of Nottingham, UK \\ *corresponding author email: theo.elmer@nottingham.ac.uk \\ *corresponding author telephone: + 44 (0)7500 831178
}

\section{Abstract}

To date, the application of liquid desiccant air conditioning systems in built environment applications, particularly small scale, has been limited. This is primarily due to large system size and complexity, issues of desiccant solution leakage and carry-over and equipment corrosion. As a result, a novel integrated desiccant air conditioning system (IDCS) has been developed. The system combines the regenerator, dehumidifier and evaporative inter-cooler into a single membrane based heat and mass exchanger. This paper presents an evaluation, based on experimental data, of the novel IDCS operating with a potassium formate $\left(\mathrm{CHKO}_{2}\right)$ desiccant working fluid. A range of tests have been completed to characterise the performance of the dehumidifier, regenerator and complete IDCS. Cooling output in the range of 570 to $1362 \mathrm{~W}$ and dehumidifier effectiveness in the range of 30 to $47 \%$ are presented. An issue encountered has been an imbalance between moisture removal rate in the dehumidifier and moisture addition rate in the regenerator. As a result, an adjusted thermal $\mathrm{COP}\left(\mathrm{COP}_{\mathrm{th}, \mathrm{adj}}\right)$ value has been calculated. $\mathrm{COP}_{\text {th,adj }}$ values of 1.26 have been achieved with an average of 0.72 . Electrical COP $\left(\mathrm{COP}_{\mathrm{el}}\right)$ values of 3.67 have been achieved with an average of 2.5.

The work demonstrates that the novel IDCS concept is viable and has provided progress to the field of liquid desiccant air conditioning technology for building applications. Further work is required in order to address the main issue of mass imbalance between the dehumidifier and regenerator.

Keywords: Liquid desiccant, air conditioning, integrated design, building application, potassium formate. 


\section{Introduction}

Buildings use significant quantities of energy, and thus they are a great contributor to $\mathrm{CO}_{2}$ emissions. Heating, ventilation and air conditioning (HVAC) systems are a major source of this energy use in buildings, accounting for around $50 \%$ of total supplied energy [1]. Air conditioning is a major function within HVAC systems, and is widely used in a range of buildings such as homes, schools, supermarkets and sport centres. Although air conditioning has become a part of people's life needs in many Middle East, Far East, American and Southern European regions, it has more recently received growing use in Northern European countries, such as the UK, Denmark and Germany. This is due to more frequent warm spells, improved building insulation / air tightness and the use of in-house heat generating appliances [2].

Currently, the air conditioning market is dominated by vapour compression systems (VCS) because they have good stability in performance, low cost, long life and a reasonable electrical COP $\left(\mathrm{COP}_{\mathrm{el}}\right)$ of between 2 - 4 [3]. However, VCS make use of harmful refrigerants such as R-22, R-410A, R-134A, materials with high global warming potential [4], and use significant quantities of electrical energy to drive the compressor. Owing to the fact that the most common form of electrical generation in the majority of counties is from the combustion of fossil fuels, VCS can be viewed as neither a sustainable nor efficient air conditioning option [5]. It is thus apparent, with an already high and continually growing global demand for air conditioning there is a need for alternative options that do not rely so heavily on harmful working fluids and fossil fuel derived electrical energy.

\subsection{Alternative air conditioning technologies}

There are a variety of alternative air conditioning systems; foremost amongst these are the sorption technologies, which reduce the requirement of electrical energy, but in place of this, increase the demand for thermal energy to operate. This thermal energy can be sourced from waste (process), solar, fuel cell etc. Thus, the associated $\mathrm{CO}_{2}$ emissions in waste heat driven cooling cycles will be lower than an equivalent VCS, primarily due to a reduction in electrical requirement and the utilisation of waste/renewable heat for $a$ useful process.

Closed cycle vapour absorption systems (VAS) replace the electrical driven compressor found in a VCS with a heat driven absorber and generator, these act in combination as a thermal compressor. VAS have a relatively low thermal $\mathrm{COP}\left(\mathrm{COP}_{\mathrm{th}}\right)$, in the range of 0.5 
in single effect cycles up to 1.2 in double effect cycles $[3,6]$, which results in the intensive use of thermal energy. Furthermore, due to pressurised operation, the need for high temperature waste heat, expensive and corrosive chemical solutions, e.g., $\mathrm{LiCl}$, $\mathrm{LiBr}, \mathrm{CaCl}_{2}$, VAS are relatively large and complex, and this has limited their attraction to many users [7] and to applications greater than 10kW [8]. Thus, a VAS cannot be viewed as a viable option, particularly for smaller (domestic) building applications.

An alternative to closed cycle vapour absorption is open cycle vapour absorption; also known as desiccant air conditioning. Desiccant air conditioning utilises the capability of desiccant materials to remove moisture from an air stream by the natural sorption process. Desiccant systems operate at atmospheric pressure and can either be solid (adsorption) or liquid (absorption). Both types have their advantages and disadvantages. Liquid desiccants have lower regeneration temperatures, greater dehumidification capacity and a lower air side pressure drop. Solid desiccants systems are compact, simple, less subject to desiccant carryover and corrosion [9]. In this paper a liquid desiccant system is presented.

A liquid desiccant air conditioning system consists of three main components: (1) dehumidifier (2) regenerator / regeneration heat source, and (3) an optional sensible cooling device. The role of the dehumidifier is to reduce the moisture content and temperature of supply air to provide a comfortable building environment for occupants. As moisture is absorbed by the liquid desiccant solution it becomes dilute and its ability to absorb moisture is reduced. In order to re-use the desiccant solution, a regenerator is used to evaporate off the moisture gained, thus increasing its concentration. The desiccant solution needs to be cooled prior to it being re-used in the dehumidifier. This is to enhance the dehumidification capacity of the solution and/or provide air sensible cooling. The solution / air sensible cooling process is most commonly achieved through evaporative means and can be a separate or con-current process to dehumidification.

The most commonly used liquid desiccant solutions used in air conditioning applications are known as halide salts, these include, Lithium Chloride ( $\mathrm{LiCl}$ ), Lithium Bromide ( $\mathrm{LiBr}$ ) and Calcium Chloride $\left(\mathrm{CaCl}_{2}\right)$. Advantages of these materials are they are there strong desiccants. $\mathrm{LiBr}$ and $\mathrm{LiCl}$ can dry air to a relative humidity of $6 \%$ and $11 \%$ respectively [10]. However the halide salts are extremely corrosive and cause significant damage to air conditioning equipment (heat exchangers, pipes etc.). Titanium is one of the few materials that can be used, however it is very expensive. In response to the shortcomings of the halide salts, other options have been explored. Salts of weak 
107 organic acids such as potassium formate $\left(\mathrm{CHKO}_{2}\right)$ or sodium formate (HCOONa) have 108 been used [11]. These solutions have low toxicity and viscosity, are neither corrosive nor

109

110

111

112

113

114

115

116

117

118

119

120

121

122

123

124

125

126

127

128

129

130

131

132

133

134

135

136

137

138

139

140

141

142

143 volatile, and they can, at the correct concentrations achieve sufficient dehumidification for comfort air conditioning in building applications. The concentration of $\mathrm{CHKO}_{2}$ for air conditioning applications needs to be greater than that of the halide salts. For instance $\mathrm{CHKO}_{2}$ at a $50 \%$ solution mass concentration is equivalent to the dehumidification potential of $\mathrm{LiCl}$ at a $27 \%$ solution mass concentration. Although it is a weaker desiccant than the halide salts, $\mathrm{CHKO}_{2}$ ability to dehumidify air below $30 \%$ relative humidity and its favourable physical characteristics makes it an attractive option for building air conditioning applications [10].

A recent study of a liquid desiccant enhanced evaporative air conditioning system demonstrated a 30 - $90 \%$ reduction in energy demand compared to an equivalent VCS [12]. Desiccant systems are currently competing in applications with large latent loads such as supermarkets and where high humidity may cause damage to property such as storage areas [11]. Although extensive work has been carried out on liquid desiccant air conditioning [13-17], system complexity and large geometrical size has severely limited their wider application and outweighed the significant energy savings they can achieve [9]. There is therefore a great need for simpler, more compact systems, particularly for building applications where space is often limited. Another major issue reported with liquid desiccant air conditioning systems is carry-over of the liquid desiccant solution into the supply airstream. This presents a health hazard to occupants and a corrosion risk for air conditioning plant and building. Liquid desiccant carry-over may be eliminated with the introduction of a semi permeable micro-porous membrane which allows the diffusion of water vapour but prevents the liquid desiccant solution migrating across it [18].

In response to these operational issues, a novel IDCS has been developed with the aim of permitting effective integration of liquid desiccant air conditioning in building applications. The novel IDCS has three design characteristics that aim to address the issues of system size and complexity, desiccant solution leakage and carry-over and equipment corrosion.

(1) A novel stack design integrates the regenerator, dehumidifier and evaporative inter-cooler into a single heat and mass exchanger (HMX), making the whole system more compact and less prone to leakage. The IDCS has less piping, heat exchangers and pumps compared to an equivalent conventional 'separate' system. 
(2) The use of a semi-permeable micro porous membrane in the dehumidifier and regenerator HMX cores to prevent desiccant entrainment into the supply / working airstreams.

(3) Employment of an environmentally friendly, non-corrosive and low cost $\mathrm{CHKO}_{2}$ desiccant solution.

This paper presents an evaluation, based on experimental data, of the novel IDCS operating with a $\mathrm{CHKO}_{2}$ desiccant working fluid. No previous work has been found in the literature regarding an integrated design of this type. The work presented provides progress to the field of liquid desiccant air conditioning technology for building applications.

\section{Experimental set-up}

As previously stated, space, complexity and leakage is often cited as a significant barrier to the wider use of liquid desiccant air conditioning in buildings. As a result, an efficient and compact liquid desiccant system has been designed and built. The regenerator $(R / C)$, dehumidifier $(D / C)$ and evaporative inter-cooler $(E / C)$ are combined into one single HMX core. The membrane HMX runs the entire length of the unit, but is subdivided into three different airflows, and two different fluid flows; desiccant and water. Thermal input to the regenerator is achieved through the heating of the inlet airstream in a liquid to air heat exchanger. Figure 1 shows a schematic of the integrated unit design concept. This design significantly reduces the number of heat exchangers, pipes and ducting often seen in liquid desiccant air conditioning systems, therefore reducing its total footprint.

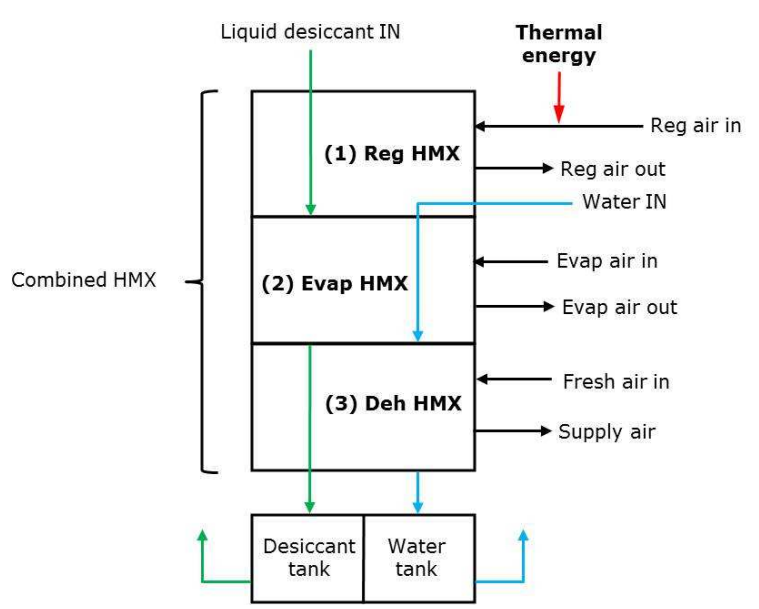


172 The novel IDCS design has three distinct advantages:

173

1. More compact form, essential for buildings applications

175

2. Reduced risk of desiccant leakage

Figure 2 provides a labelled schematic of the IDCS laboratory set-up including instrumentation and controls. A hot water cylinder is used as the regenerator thermal input.

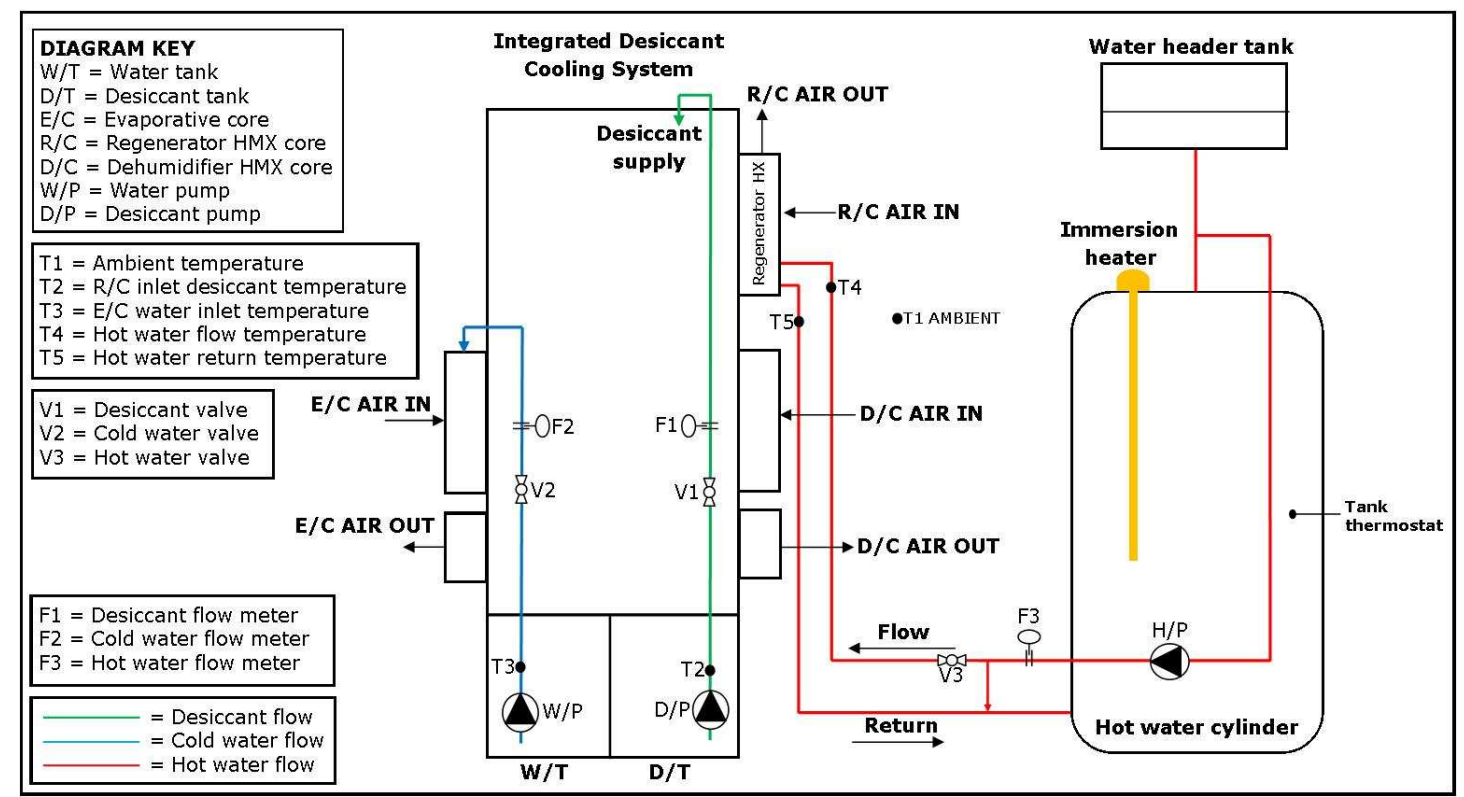

Figure 2 System schematic of the IDCS laboratory set-up

The IDCS HMX core consist of 26 channels that allow air and desiccant solution / water to flow in a cross flow manner (air through the core, desiccant / water downwards through the core), separated by a semi permeable micro-porous membrane. The solution channels consist of a polyethylene sheet, with membranes attached on either side. The gap between the two solution channels provides the space for the air to flow. The membrane allows the diffusion of water vapour, but prevents liquid desiccant solution migrating across it, thus overcoming the issue of liquid desiccant entrainment in the air stream. The regenerator core is $310 \mathrm{~mm}$ in height, $420 \mathrm{~mm}$ in width and has a depth of $240 \mathrm{~mm}$, with 26 air channels. The dehumidifier and evaporative inter-cooler core is $695 \mathrm{~mm}$ in height, $420 \mathrm{~mm}$ in width and has a depth of $240 \mathrm{~mm}$, with 26 air channels. The entire HMX core is contained in an aluminium box. The membrane HMX core sits on top of a 20 litre stainless steel split desiccant $(D / T)$ and water tank $(W / T)$. Weak desiccant 
solution is pumped, using a $15 \mathrm{~W}$ single phase centrifugal magnetically driven pump (010L. $\mathrm{min}^{-1}$ ), from the desiccant tank to the top of the unit where the regenerator is located. Here the desiccant is supplied through a spray nozzle, and flows in a downward direction due to gravity, contained within the membrane. Thermal energy is supplied to the regenerator by heating the regenerator airstream prior to it entering the regenerator HMX using a liquid to air heat exchanger. Heating of the airstream lowers the air side vapour pressure and thus drives mass transfer from the desiccant solution. Direct solution heating is not used due to the integrated design. The regenerator airstream is supplied to the unit via a $500 \mathrm{~m}^{3} \cdot \mathrm{hr}^{-1}$ (nominal) $240 \mathrm{~V}$ AC axial fan. The experimental work presented uses a vented 120 litre hot water cylinder with a $3 \mathrm{~kW}$ electrical immersion heater as the regenerator heat source. However, the electrical immersion heater could be replaced with any heat source that can provide hot water at the desired temperature and flow rate i.e. waste, solar. A Wilo-Smart A-rated $230 \mathrm{~V}$ AC pump has been employed to circulate the hot water in the heating circuit. A Honeywell L641A cylinder thermostat has been used to maintain the flow temperature from the tank at a constant temperature. The heated regenerator air stream then passes across the desiccant soaked membrane causing the dilute desiccant solution to be re-concentrated due to the removal of water by vaporisation into the regenerator air stream. The liquid desiccant leaves the regenerator as concentrated (strong) solution. The structure of the regenerator core is shown in Figure $3 a$ and a photograph in Figure $3 b$. One side of the regenerator exchanger is blanked off. This is because in the regeneration process only one airstream is required, that to regenerate the desiccant solution. However, in the lower section of the IDCS there are two air processes, evaporative cooling and dehumidification, and so two air channels are required, as shown in Figure 4a.

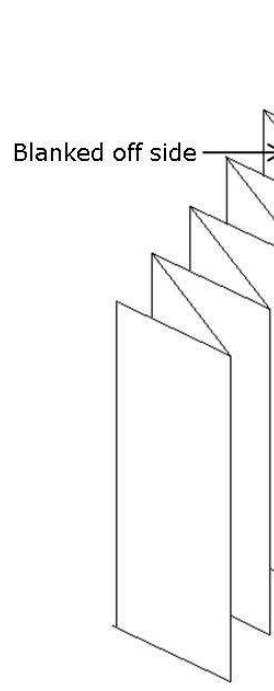

Desiccant solution from storage tank

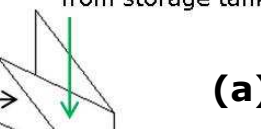

(a)

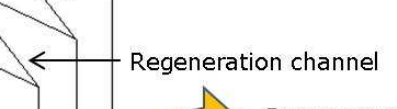

Regenerator air outlet 
After the regeneration process, the desiccant solution flows downwards due to gravity through the desiccant evaporative inter-cooler and dehumidifier. Here two processes occur simultaneously, (1) an evaporative cooling process creates a sensible cooling effect, which is transferred across the HMX wall to cool the desiccant solution and supply air stream, and (2) the supply air stream is dehumidified and cooled. The structure of the evaporative inter-cooler and dehumidifier core is shown in Figure $4 \mathrm{a}$ and $a$ photograph in Figure $3 \mathrm{~b}$ and Figure $4 \mathrm{~b}$. The evaporative cooling process is not only advantageous for the lowering of the supply air temperature; it also removes the latent heat of condensation produced during the dehumidification process and creates a lower vapour pressure in the desiccant solution and thus a greater dehumidification potential.
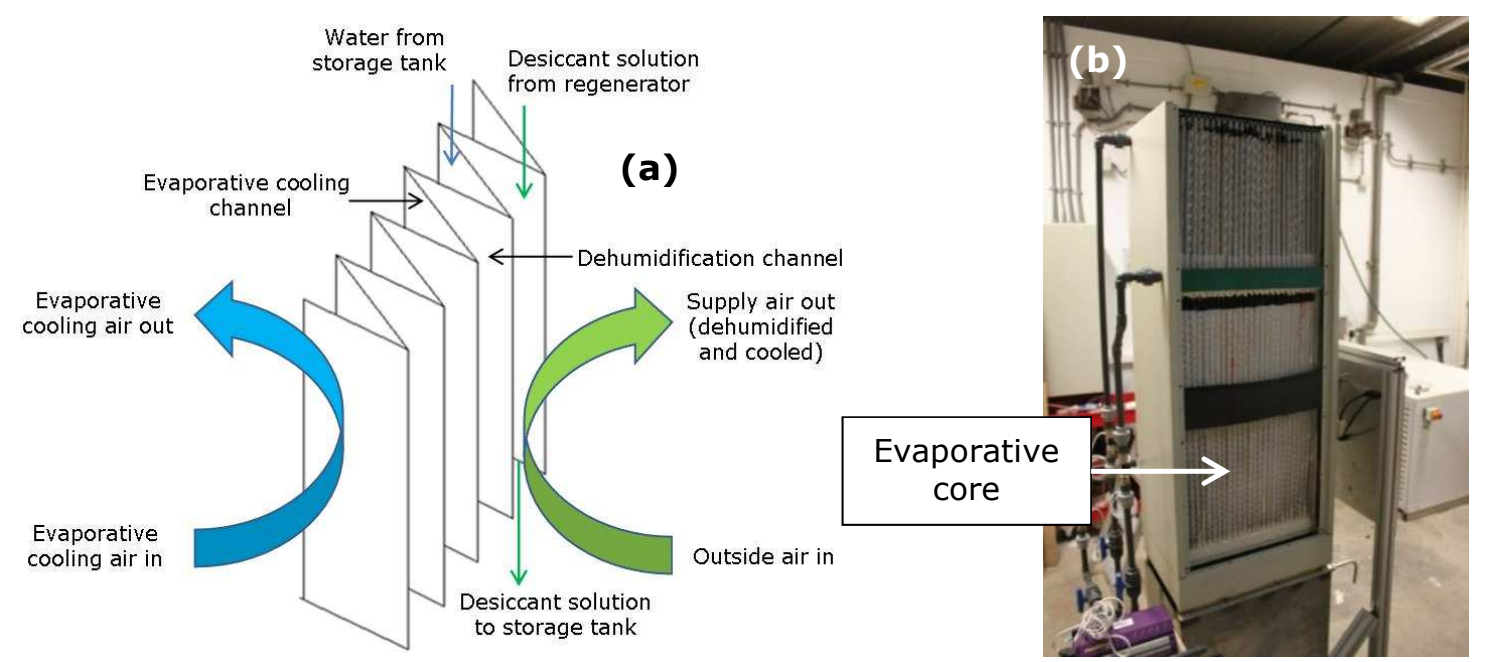

Figure 4 (a) Desiccant evaporative inter-cooler and dehumidifier operating concept, and (b) photograph of dehumidifier

Water is pumped using a $15 \mathrm{~W}$ single phase centrifugal magnetically driven pump (010 L. $\mathrm{min}^{-1}$ ) from the water tank to the top of the evaporative core and is supplied through a spray nozzle. On the evaporative side of the HMX, water flows downwards due to gravity over the exchanger surface. The evaporative cooler airstream is supplied via a $500 \mathrm{~m}^{3} \cdot \mathrm{hr}^{-1}$ (nominal) 240V AC axial fan. This air flows across the HMX in a cross-flow manner. This causes direct evaporative cooling and indirectly cools, through the exchanger wall, the liquid desiccant solution and dehumidifier supply air stream. Because the evaporative cooling and dehumidification processes are separated by the exchanger wall, sensible cooling is provided to the desiccant solution and supply airstream without moisture addition. On the dehumidifier side of the HMX, fresh air is supplied to the HMX core via a $500 \mathrm{~m}^{3} \cdot \mathrm{hr}^{-1}$ (nominal) $240 \mathrm{~V} \mathrm{AC}$ axial fan. The fresh air flows in a cross flow manner across the desiccant soaked membrane. Due to the lower temperature (evaporatively cooled) and vapour pressure (regenerated) of the desiccant solution, the air is sensibly cooled and dehumidified. This air can then be supplied directly to the 
room, or can be passed through another evaporative cooling process to lower its temperature further. The warm and weak desiccant solution then flows back to the desiccant tank to begin the process again. The water used in the evaporative inter-cooler flows back to the separate tank.

Many of the liquid desiccant systems reported in the literature directly heat and cool the desiccant solution prior to the regeneration and dehumidification processes. However, in the IDCS because all desiccant flow is contained within one complete HMX the desiccant solution cannot be extracted for prior heating and cooling, thus heating of the regenerator air stream and the inclusion of an evaporative inter-cooler are required.

\subsection{Instrumentation}

All fans on the IDCS are equipped with Vent Axia infinitely variable fan speed controllers to enable control of the volumetric air flow through the HMX cores. The air inlet and outlet of the regenerator, dehumidifier and evaporative HMX cores are fitted with $125 \mathrm{~mm}$ galvanised steel spiral tube ducting. The inlet and outlet air flows are instrumented with Vaisalia HMP110 humidity and temperature probes. The probes are mounted within the spiral tube ducting using special flanges. The humidity and temperature probes are factory calibrated. Air velocity through the regenerator, dehumidifier and evaporative inter-cooler cores are measured using an RS AM4204 hot wire anemometer at the air ducting outlets. The hot wire anemometer is factory calibrated. Air velocity measurements are recorded at five points across the air duct, and the average taken. The air velocity measurements are also validated against a TSI LCA501 rotating vane anemometer.

The desiccant and water pipes connecting the tank to the HMX core have been equipped with ball valves (V1 and V2 in Figure 2) so that the desiccant or water volumetric flow rate may be set to a desired value. A valve has also been placed on the hot water circuit (V3) to control the hot water flow to the regenerator. All water and desiccant solution flows have been instrumented with sheathed K-Type thermocouples (Nickel Chromium/Nickel Aluminium). Thermocouples have been placed at the inlet to the desiccant side (T2) and water side (T3) of the HMX core. Thermocouples have also been placed at the hot water inlet (T4) and outlet (T5) to the regenerator liquid to air heat exchanger. 
289 The desiccant solution and water volumetric flow is measured using a 0.2 to $2 \mathrm{~L}$. $\mathrm{min}^{-1}$ 290 Parker Liquid Flow Indicator. These are placed on the pipe connecting the tank to the 291 HMX core (F1 on desiccant side, and F2 on water side). The flow meters used are 292 calibrated for water at $20^{\circ} \mathrm{C}$ according to density and viscosity. Thus, for the water flows 293 used in the system, no correction is required. For the desiccant solution flow a correction 294 factor is required to equate the volumetric flow shown on the flow meter to the actual 295 desiccant flow. This correction correlation is shown in Equation 1 [19].

$$
v_{\text {sol }}=v_{\mathrm{w}} \sqrt{\frac{\left(m_{\text {float }}-V_{\text {float }}^{\prime} \rho_{\text {sol }}\right) \rho_{\mathrm{w}}}{\left(m_{\text {float }}-V_{\text {float }}^{\prime} \rho_{\mathrm{w}}\right) \rho_{\text {sol }}}}
$$

298

299

$v_{\text {sol }}$ and $v_{\mathrm{w}}$ is the volumetric flow in L. $\min ^{-1}$ of the desiccant solution and water 300 respectively. For the flow meters used the float weight, $m_{\text {float }}=2.1 \times 10^{-3} \mathrm{~kg}$ and the float volume $V_{\text {float }}^{\prime}=0.25 \times 10^{-6} \mathrm{~m}^{3}$.

302

303

The hot water cylinder is equipped with an RS $1-15 \mathrm{~L} \cdot \mathrm{min}^{-1}$ piston flow meter (F3), designed for flow temperatures of up to $60^{\circ} \mathrm{C}$. All desiccant solution and water flows on the IDCS are equipped with $20 \mathrm{~mm}$ PVC-U plastic pipe, with plastic fittings. The hot water cylinder is piped with insulated $22 \mathrm{~mm}$ copper pipe and copper fittings. Flexible PVC hot water hose is used to connect the hot water cylinder to the regenerator liquid to air heat exchanger.

309

For the accurate evaluation of the desiccant system, the working concentration of the desiccant solution needs to be determined. Using a correlation based on the work of Melinder [20] the desiccant solution concentration is determined from the solution density $\left(\rho_{\text {sol }}\right)$ and temperature $\left(T_{\text {sol }}\right)$. In the experimental work the density of the desiccant solution is measured using a differential pressure density meter with temperature compensation. The meter has been designed to work in the density range of the $\mathrm{CHKO}_{2}$ solution (1400 to $1550 \mathrm{~kg} \cdot \mathrm{m}^{-3}$ ) and has been calibrated with water. The measurement prongs of the differential pressure density meter are placed in the desiccant solution tank and held until a steady-state reading is achieved. The temperature of the solution is measured using the K-Type thermocouple at the tank outlet. The concentration is then calculated using the correlation presented in Equation 2. 


$$
\begin{gathered}
X_{\text {sol }}=-253.147703+0.0443853996 T_{\text {sol }}+0.000163666247 T_{\text {sol }}{ }^{2}+0.331709855 \rho_{\text {sol }} \\
-0.0000793702671 \rho_{\text {sol }}{ }^{2}
\end{gathered}
$$

325 The electrical consumption of fans and pumps are measured using a Brennenstuhl 326 PM230 electricity monitor. This is essential for the $\mathrm{COP}_{\mathrm{el}}$ calculations. At full load the 327 desiccant system parasitic electrical load is measured at 400W. A DataTaker DT500 328 datalogger is used to record the data from the sensors every ten seconds.

330 Further details of the measuring equipment used and their associated accuracy are listed

\begin{tabular}{|c|c|c|c|}
\hline $\begin{array}{c}\text { Measurement } \\
\text { device }\end{array}$ & $\begin{array}{l}\text { Measurement } \\
\text { subject }\end{array}$ & $\begin{array}{l}\text { Measurement } \\
\text { range }\end{array}$ & $\begin{array}{l}\text { Measurement } \\
\text { accuracy }\end{array}$ \\
\hline $\begin{array}{l}\text { HMP110 relative } \\
\text { humidity and } \\
\text { temperature probe }\end{array}$ & $\begin{array}{l}\text { Air relative humidity } \\
\text { and temperature }\end{array}$ & $\begin{array}{c}0 \text { to } 90 \% \mathrm{RH} \\
0 \text { to } 40^{\circ} \mathrm{C}\end{array}$ & $\begin{array}{c}\mathrm{RH}_{\mathrm{a}}= \pm 1.7 \% \mathrm{RH} \\
T_{\mathrm{a}}= \pm 0.2^{\circ} \mathrm{C}\end{array}$ \\
\hline $\begin{array}{l}\text { RS AM4204 hot } \\
\text { wire anemometer }\end{array}$ & Air velocity & 0 to $20 \mathrm{~m} \cdot \mathrm{s}^{-1}$ & $u_{\mathrm{a}}= \pm 5 \%$ of reading \\
\hline $\begin{array}{c}\text { K-Type } \\
\text { thermocouple } \\
\text { probe }\end{array}$ & $\begin{array}{l}\text { Desiccant solution and } \\
\text { water temperature }\end{array}$ & 0 to $1100^{\circ} \mathrm{C}$ & $T_{\text {sol }} / T_{\text {water }}= \pm 2.2^{\circ} \mathrm{C}$ \\
\hline $\begin{array}{l}\text { Parker Liquid Flow } \\
\text { Indicator }\end{array}$ & $\begin{array}{l}\text { Desiccant solution and } \\
\text { water volumetric flow }\end{array}$ & 0.2 to 2 L. $\mathrm{min}^{-1}$ & $\begin{array}{c}v_{\text {sol }} / v_{\text {water }}= \pm 2 \% \text { of } \\
\text { reading }\end{array}$ \\
\hline $\begin{array}{l}\text { Desiccant solution } \\
\text { density meter }\end{array}$ & $\begin{array}{c}\text { Desiccant solution } \\
\text { density }\end{array}$ & $\begin{array}{c}1400-1550 \\
\mathrm{~kg} \cdot \mathrm{m}^{-3}\end{array}$ & $\rho_{s o l}= \pm 10 \mathrm{~kg} \cdot \mathrm{m}^{-3}$ \\
\hline $\begin{array}{c}\text { Brennenstuhl } \\
\text { PM230 electricity } \\
\text { monitor }\end{array}$ & $\begin{array}{c}\text { IDCS electrical power } \\
\text { usage }\end{array}$ & Up to $16 \mathrm{Amps}$ & $\begin{array}{c}W_{I D C S}= \pm 3 \% \text { of } \\
\text { reading }\end{array}$ \\
\hline
\end{tabular}

Table 1 Instrumentation equipment and associated accuracy

\subsection{Uncertainty analysis}

336 Uncertainty analysis provides a measure of the error associated with a calculated value.

337 Using the propagation of error formula [21] the absolute uncertainty of a calculated 338 value can be calculated. The maximum relative uncertainty values for the dehumidifier, regenerator and complete system performance studies are presented in their respective experimental results section. Absolute uncertainty values for six sample dehumidifier, regenerator and system performance studies are shown in Table 4 - Table 6 respectively.

342 It has been identified that the largest source of error comes from the relative humidity 343 measurement which is fundamental to all calculations. The K-Type thermocouples are also a large source or error and fundamental to the COP calculations. 


\subsection{Experimental method}

347 The IDCS is installed at The University of Nottingham's Marmont Laboratory. This is to 348 facilitate evaluation under varying environmental and operating conditions in controlled 349 laboratory conditions. There are three main components to the laboratory experimental set-up shown in Figure 5: (1) the novel IDCS, (2) hot water cylinder and (3) environmental chamber. Table 2 provides IDCS air flow identification.

352

353

354

355

356

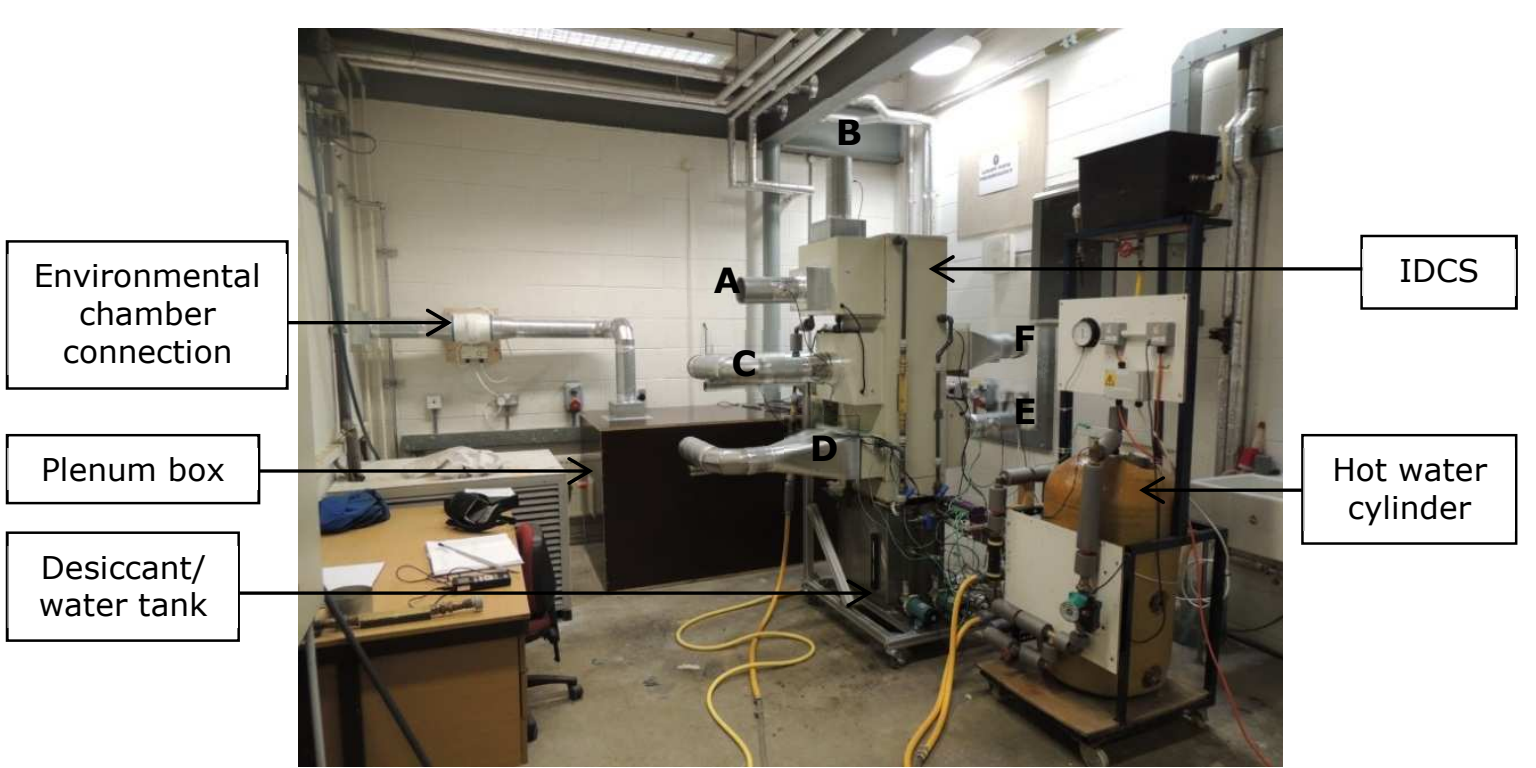

Figure 5 IDCS laboratory setup with labelled air flows

Table 2 IDCS air flow identification

\begin{tabular}{cccc}
\hline Air flow ID & Air flow description & Air flow ID & Air flow description \\
\hline A & Regenerator HMX inlet & D & Dehumidifier HMX outlet \\
B & Regenerator HMX outlet & E & Evaporative cooler inlet \\
C & Dehumidifier HMX inlet & F & Evaporative cooler outlet \\
\hline
\end{tabular}

The use of the environmental chamber facilitates: (a) a high level of control and provides consistent inlet air conditions to the IDCS throughout all tests, and (b) simulation of different climates other than the UK; specifically those that favour the use of liquid desiccant air conditioning i.e. high humidity. The environmental chamber can create air conditions from 0 to $40^{\circ} \mathrm{C}$ and 10 to $80 \%$ relative humidity. The dehumidifier (supply) air stream is connected to the environmental chamber by the way of a plenum box. However, the regenerator and evaporative inter-cooler air streams use the air from the laboratory environment. This is because the complete IDCS could not fit in the environmental chamber, and the air flow requirements of the entire IDCS were too high to duct all air flows from the chamber to the IDCS. The desiccant evaporative inter- 
cooler will perform better with laboratory (room) air as opposed to environment chamber (outside) air as it is drier and thus represents a greater evaporative potential. Similarly, the regenerator will perform better with lower humidity laboratory air because it possesses a lower vapour pressure. Therefore using laboratory (room) air for the evaporative and regeneration processes will improve system performance. All outlet air flows are to the laboratory environment.

At the beginning of a test, the temperature and relative humidity of the environmental chamber are set. Depending on the requirements it can take up to one hour to achieve stable and homogenous air conditions inside. The temperature and relative humidity shown on the chambers display panel is cross checked against the Vaisalia HMP110 humidity and temperature probe at the IDCS dehumidifier inlet and an RS 1365 handheld humidity-temperature meter within the chamber. Once the desired air conditions are achieved, and depending on the test variable under investigation, the IDCS operation is set accordingly and run at that condition.

For desiccant solution regeneration, a vented 120 litre hot water cylinder with a 3kW electrical immersion heater is used as the thermal input. Before the start of a test the hot water tank heater and circulation pump (H/P) are switched on. A by-pass loop is used to circulate the water around the tank until it reaches the desired temperature for the particular test. A control valve (V3) on the flow pipe is used to provide the desired hot water flow to the IDCS. The tank thermostat is set according to the required flow temperature. The flow temperature from the tank is checked at regular intervals.

The desiccant solution concentration in the tank is recorded at the start, middle and end of each separate test, and the result recorded. The air velocity is measured at each duct outlet and recorded at the beginning of each test, and the result recorded. Multiplication of the average air velocity by the air duct area provides the volumetric air flow through the HMX cores. The desiccant solution and water volumetric flows are measured at the start of a test, and the flow indictors checked periodically throughout a test. Depending on the test variable being investigated, tests last for 30-60 minutes or until steady-state outlet air conditions are achieved for extended periods (30 minutes or more). Data is recorded every ten seconds in this period. Only steady-state data is used in the performance evaluation. Testing of the dehumidifier and regenerator components are carried out con-currently. This is due to the operational nature of the combined IDCS. For each variable investigated there were a minimum of three individual tests conducted. The results presented are the average of each of these tests. 


\subsubsection{Performance evaluation metrics}

406 The performance of the dehumidifier is evaluated on the basis of moisture removal rate, 407 change in absolute humidity of air across the dehumidifier, latent heat transfer 408 (dehumidifier) effectiveness and cooling output.

410 The dehumidifier moisture removal rate (MRR) in $\mathrm{g} \cdot \mathrm{s}^{-1}$ is shown in Equation 3.

$$
\operatorname{MRR}=\dot{m}_{a, d e h}\left(\omega_{a, \text { in }, \text { deh }}-\omega_{a, \text { out }, \text { deh }}\right)
$$

$414 \dot{m}_{a, d e h}$ is the mass flow of rate air passing through the dehumidifier HMX core in $\mathrm{kg} . \mathrm{s}^{-1}$. $415 \omega_{a, \text { in,deh }}$ and $\omega_{a, \text { out,deh }}$ are the dehumidifier's respective inlet and outlet air absolute 416 humidity in $\mathrm{kg}_{\text {vapour }} / \mathrm{kg}_{\text {dryair }}$.

418 The change in the absolute humidity $\left(\mathrm{kg}_{\text {vapour }} / \mathrm{kg}_{\text {dryair }}\right)$ of air across the dehumidifier is 419 shown in Equation 4.

420

$$
\Delta \omega_{d e h}=\omega_{a, i n, d e h}-\omega_{a, o u t, d e h}
$$

423 The latent heat transfer (dehumidifier) effectiveness, shown in Equation 5, is the ratio of 424 actual moisture transferred to the maximum moisture transfer.

425

$$
\eta_{L}=\frac{\omega_{a, i n, d e h}-\omega_{a, o u t, d e h}}{\omega_{a, i n, d e h}-\omega_{e q, d e h}}
$$

427

$428 \omega_{\text {eq }}$ is the equivalent moisture content in $\mathrm{kg}_{\text {vapour }} / \mathrm{kg}_{\text {dryair }}$ of the desiccant solution at the 429 inlet condition, and is a function of its concentration and temperature as shown in 430 Equation 6.

$$
\omega_{e q}=0.622\left(\frac{p_{\text {sol }}\left(X_{\text {sol }}, T_{\text {sol }}\right)}{p_{\text {atm }}-p_{\text {sol }}\left(X_{\text {sol }}, T_{\text {sol }}\right)}\right)
$$

$434 p_{\text {sol }}$ is the vapour pressure in $\mathrm{Pa}$ of the desiccant solution at a specified concentration and 435 temperature. $p_{\text {atm }}$ is atmospheric pressure and is equal to $101325 \mathrm{~Pa}$. $X_{\text {sol }}$ is the desiccant 
solution mass concentration, determined using Equation 2. $T_{\text {sol }}$ is the solution

437 temperature in ${ }^{\circ} \mathrm{C}$.

439 The dehumidifier cooling output in $\mathrm{W}$ is shown in Equation 7:

440

$$
\dot{Q}_{\text {cooling }}=m_{a, d e h}\left(h_{a, \text { in }, \text { deh }}-h_{a, \text { out }, \text { deh }}\right)
$$

442

$443 h_{a, \text { in, deh }}$ and $h_{a, \text { out,deh }}$ are the respective inlet and outlet specific enthalpies of the air 444 entering and leaving the dehumidifier $\mathrm{HMX}$ core in $\mathrm{J} \cdot \mathrm{kg}^{-1}$. Air enthalpy is a function of 445 both temperature and absolute humidity. Therefore air cooling means lowering 446 temperature and / or absolute humidity.

448 The performance of the regenerator is evaluated on the basis of: moisture addition rate 449 and regenerator thermal input.

450

451 The regenerator moisture addition rate (MAR) in $\mathrm{g} \cdot \mathrm{s}^{-1}$ is shown in Equation 8.

452

$$
\operatorname{MAR}=\dot{m}_{a, r e g}\left(\omega_{a, \text { out }, \text { reg }}-\omega_{a, \text { in,reg }}\right)
$$

$\dot{m}_{a, \text { reg }}$ is the mass flow rate of air passing through the regenerator HMX in $\mathrm{kg} \cdot \mathrm{s}^{-1} . \omega_{\mathrm{a}, \text { out,reg }}$ and $\omega_{a, \text { in, reg }}$ are the regenerator's respective inlet and outlet air absolute humidity in $\mathrm{kg}_{\text {vapour }} / \mathrm{kg}_{\text {dryair. }}$.

The regenerator thermal input, $\dot{Q}_{\text {reg }}$ in W is determined using Equation 9.

460

$$
\dot{Q}_{\text {reg }}=\dot{m}_{w, \text { reg }} c_{p, w, \text { reg }}\left(T_{w, \text { flow }}-T_{w, \text { return }}\right)
$$

$463 \dot{m}_{w, \text { reg }}$ and $c_{p, w, r e g}$ are the respective mass flow rate in $\mathrm{kg} \cdot \mathrm{s}^{-1}$ and specific heat capacity in $464 \mathrm{~J} . \mathrm{kg}^{-1} . \mathrm{K}$ of the water in the regenerator heating circuit. $T_{\mathrm{w}, \text { flow }}$ and $T_{\mathrm{w}, \text { return }}$ are the 465 respective heating circuit flow and return water temperatures in ${ }^{\circ} \mathrm{C}$.

467 Overall IDCS performance is evaluated using $\mathrm{COP}_{\text {th }}$ and $\mathrm{COP}_{\mathrm{el}}$. These are defined in 468 Equations 10 and 11 respectively. 


$$
\operatorname{COP}_{t h}=\frac{\dot{Q}_{\text {cooling }}}{\dot{Q}_{\text {reg }}}
$$

$$
\operatorname{COP}_{e l}=\frac{\dot{Q}_{\text {cooling }}}{\dot{W}_{\text {aux }, \text { des }}}
$$

$473 \dot{W}_{\text {aux,des }}$ is the IDCS electrical requirement (fans and pumps). Depending on the test 474 conditions this ranged from $370 \mathrm{~W}-400 \mathrm{~W}$. The thermophysical properties of the humid 475 air are determined from in-built functions in Engineering Equation Solver. The 476 thermophysical properties of the desiccant solution are determined from linear 477 regression curve fits to published data [20, 22].

478

\section{Results and analysis}

480 This section presents the results and analysis from the dehumidifier, regenerator and 481 complete IDCS experimental evaluation. Due to the combined nature of the IDCS the 482 desiccant solution flow in the regenerator HMX has to equal that in the dehumidifier $483 \mathrm{HMX}$. Due to the combined and integrated nature of the system measurement of the 484 desiccant solution properties between the regenerator and dehumidifier is not possible. 485 Unless otherwise varied, Table 3 provides the operating values used in the experimental 486 evaluation of the dehumidifier, regenerator and complete IDCS.

Table 3 Operating values used in the evaluation of the IDCS

\begin{tabular}{cccc}
\hline Variable & Dehumidifier & Inter-cooler & Regenerator \\
\hline Desiccant / water flow $\left(\right.$ L.min $\left.{ }^{-1}\right)$ & 1.5 & 1.5 & 1.5 \\
Desiccant temperature $\left({ }^{\circ} \mathrm{C}\right)$ & $23-26$ & --- & --- \\
Water temperature $\left({ }^{\circ} \mathrm{C}\right)$ & --- & $22-25$ & --- \\
Solution mass concentration $(-)$ & $0.65-0.7$ & --- & $0.65-0.7$ \\
Volumetric air flow $\left(\mathrm{m}^{3} \cdot \mathrm{hr}^{-1}\right)$ & 243 & 269 & 243 \\
Inlet air temperature $\left({ }^{\circ} \mathrm{C}\right)$ & 30 & $22-26$ & $22-26$ \\
Inlet air relative humidity $(\%)$ & 60 & $38-66$ & $38-66$ \\
\hline
\end{tabular}

489

490 Throughout all tests a desiccant solution volumetric flow of $1.5 \mathrm{~L} \cdot \mathrm{min}^{-1}$ was used. It was 491 found through experimental evaluation that a volumetric flow above $1.5 \mathrm{~L} . \mathrm{min}^{-1}$ resulted 492 in desiccant solution entrainment in the supply airstream, and below $1.5 \mathrm{~L} . \mathrm{min}^{-1}$ leads to 493 insufficient wetting of the membrane surface. 


\subsection{IDCS dehumidifier component analysis}

495 The role of the dehumidifier is to cool a supply air stream through the lowering of its 496 enthalpy. Enthalpy reduction is achieved primarily through the removal of moisture from 497 the air stream to a liquid desiccant solution. Depending on the desiccant solution 498 temperature, a reduction in the supply air temperate may also occur. The IDCS 499 dehumidifier component evaluation has assessed the impact of inlet air temperature, 500 inlet air relative humidity and volumetric air flow on dehumidifier performance. Table 4 501 presents the results for six sample dehumidifier tests along with their associated 502 absolute uncertainty.

503

\section{$504 \quad 3.1 .1$ IDCS dehumidifier inlet air condition effect}

505 The IDCS dehumidifier performance has been evaluated over a 50-70\% relative humidity 506 range at a 30 and $35^{\circ} \mathrm{C}$ inlet air temperature. The data presented in Figure 6 shows that 507 dehumidifier performance improves with increasing inlet air temperature and relative 508 humidity. Figure $6 a$ shows that over the investigated relative humidity range the 509 moisture removal rate from the supply airstream increases from 0.1541 to $0.4395 \mathrm{~g} . \mathrm{s}^{-1}$ 510 for the $30^{\circ} \mathrm{C}$ inlet air condition and 0.2354 to $0.4682 \mathrm{~g} . \mathrm{s}^{-1}$ for the $35^{\circ} \mathrm{C}$ inlet air condition.

511 As the relative humidity and temperature of the inlet air increases, its vapour pressure 512 increases, and thus a greater vapour pressure difference between the humid air and 513 desiccant solution exists, driving greater mass transfer. Figure $6 \mathrm{~b}$ shows that over the 514 investigated relative humidity range the absolute humidity difference of the supply air 515 stream increases, i.e. more dehumidification occurs, from 0.001988 to $5160.005728 \mathrm{~kg}_{\text {vapour }} / \mathrm{kg}_{\text {dryair }}$ for the $30^{\circ} \mathrm{C}$ inlet air condition, and from 0.003073 to $5170.0062 \mathrm{~kg}_{\text {vapour }} / \mathrm{kg}_{\text {dryair }}$ for the $35^{\circ} \mathrm{C}$ inlet air condition. Figure $6 \mathrm{c}$ shows that over the 518 investigated relative humidity range the latent (dehumidifier) effectiveness increases 519 from 29.91 to $38.39 \%$ for the $30^{\circ} \mathrm{C}$ inlet air condition, and from 32.32 to $46.78 \%$ for the $52035^{\circ} \mathrm{C}$ inlet air condition. Figure $6 \mathrm{~d}$ shows that over the investigated relative humidity 521 range the cooling output from the dehumidifier increases as the inlet air relative 522 humidity and temperature increases. The dehumidifier cooling ranges from $570 \mathrm{~W}$ to $5231084 \mathrm{~W}$ at an inlet temperature of $30^{\circ} \mathrm{C}$, and from $1059 \mathrm{~W}$ to $1362 \mathrm{~W}$ at an inlet 524 temperature of $35^{\circ} \mathrm{C}$. The increase in cooling output with air relative humidity and 525 temperature is due to greater moisture removal rate and thus greater latent cooling, 526 plus a greater temperature difference between the air and desiccant solution leading to 527 increased sensible cooling. 

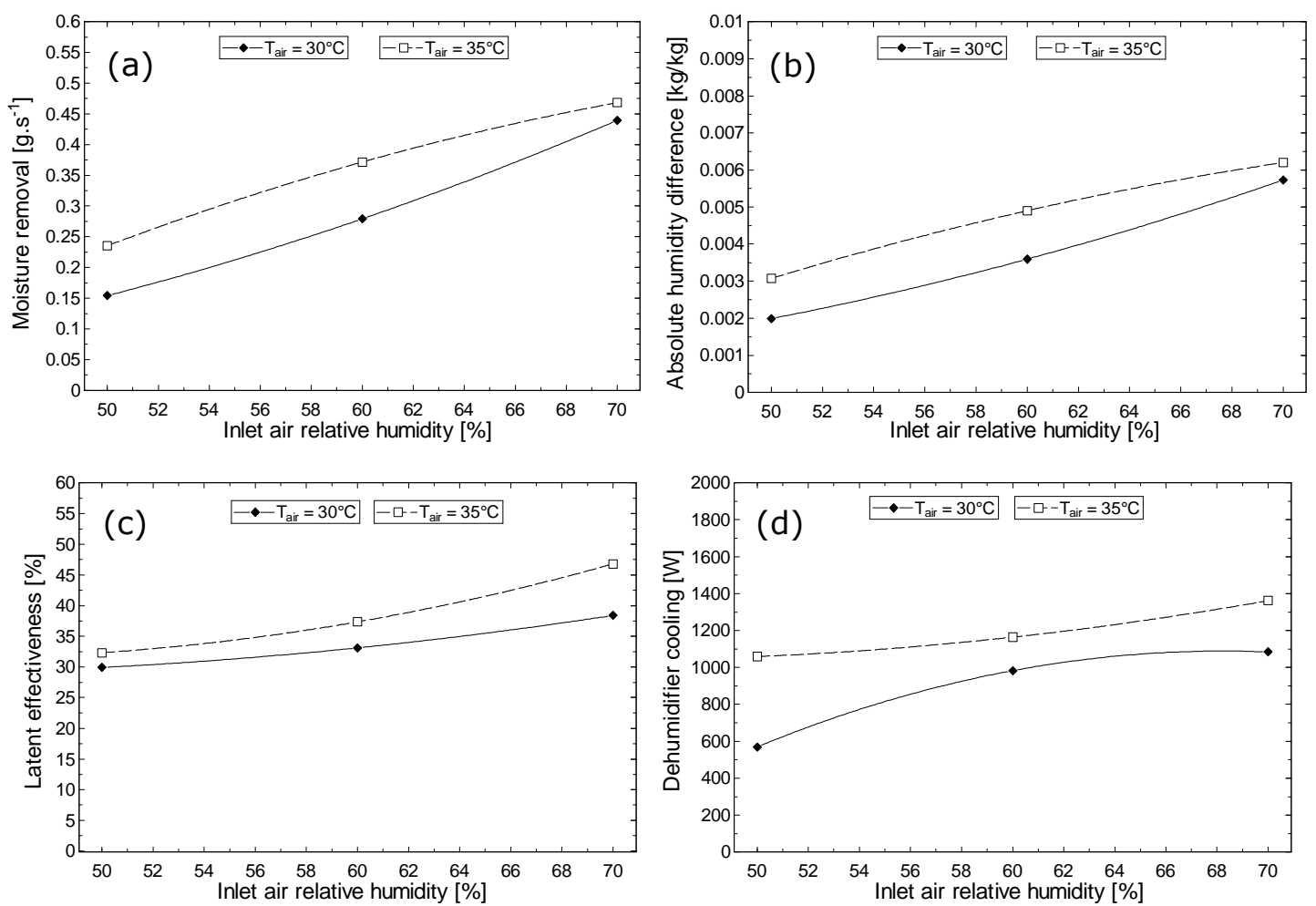

Figure 6 (a) to (d) IDCS dehumidifier performance with inlet air conditions

531

532 At the $30^{\circ} \mathrm{C}$ and $35^{\circ} \mathrm{C}$ inlet air condition, the average supply air temperatures across all 533 relative humidity tests is $28.81^{\circ} \mathrm{C}$ and $31.97^{\circ} \mathrm{C}$ respectively. From Figure 6 it is evident 534 that the IDCS dehumidifier performance improves with an increase in inlet air 535 temperature and relative humidity. The system is therefore well suited to hotter, more 536 humid climate such as Southeast Asia. However increased performance will result in a 537 greater dilution of the desiccant solution. For building applications consideration needs to 538 be given to whether the regenerator moisture addition rate achievable with the available 539 thermal input can match the mass removal rate in the dehumidifier otherwise dilution of 540 the desiccant solution over time will occur.

541

542 The IDCS evaporative inter-cooler is included to enhance performance by providing 543 sensible cooling to the dehumidification process. The evaporative inter-cooler is operated 544 on laboratory air. Figure 7 shows the relationship between the inlet air absolute humidity 545 to the evaporative inter-cooler and the cooling it provides. The cooling output is 546 determined based on the enthalpy difference of the inter-cooler's inlet and outlet air. At 547 an inlet air condition of $0.007 \mathrm{~kg}_{\text {vapour }} / \mathrm{kg}_{\text {dryair }}$ around $800 \mathrm{~W}$ of cooling is achieved, this 548 reduces to around $400 \mathrm{~W}$ at a $0.011 \mathrm{~kg}_{\mathrm{vapour}} / \mathrm{kg}_{\mathrm{dryair}}$ inlet air condition. At lower inlet air 549 absolute humidity values, the evaporative cooler produces a greater cooling output due 550 to the inlet air having a lower wet-bulb temperature and thus greater evaporative 
551 potential. As a result, in a building application it is recommended to operate the 552 evaporative inter-cooler on drier room air, as opposed to fresh outside (humid) air.

554

555

556

557

558

559

560

561

562

563

564

565

566

567

568

569

570

571

572

573

574

575

576

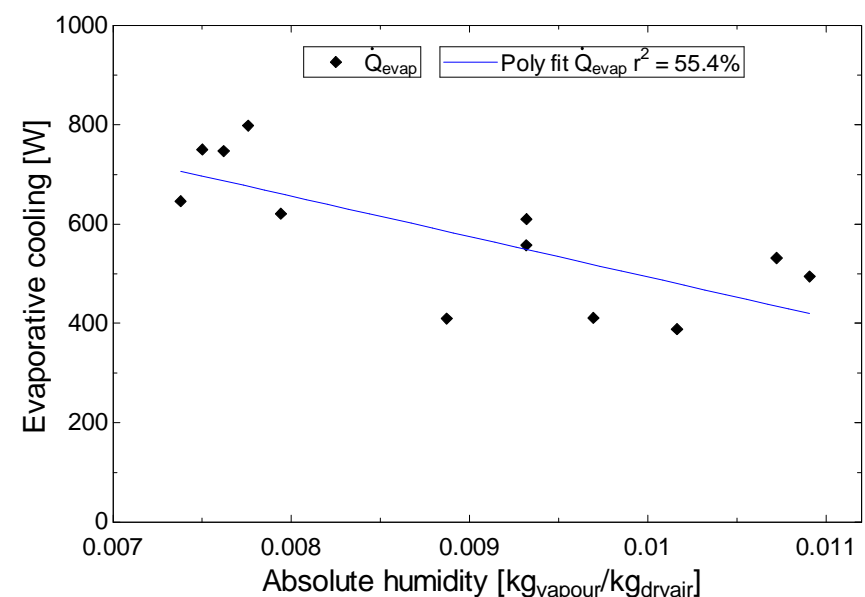

Figure 7 IDCS evaporative-inter cooler output with inlet air absolute humidity

\subsubsection{IDCS dehumidifier volumetric air flow effect}

Figure 8 shows the impact inlet air volumetric flow has on dehumidifier performance at a set inlet condition of $30^{\circ} \mathrm{C}$ and $60 \%$ relative humidity. Figure $8 \mathrm{a}$ shows the moisture removal rate increases with volumetric air flow, from $0.2058 \mathrm{~g} . \mathrm{s}^{-1}$ at $124 \mathrm{~m}^{3} . \mathrm{hr}^{-1}$ (fan setting 1 ) to a maximum of $0.2978 \mathrm{~g} \cdot \mathrm{s}^{-1}$ at $243 \mathrm{~m}^{3} \cdot \mathrm{hr}^{-1}$ (fan setting 3 ). There is little difference $\left(<0.0116 \mathrm{~g}^{-1} \mathrm{~s}^{-1}\right)$ between the moisture removal rate achieved between $217 \mathrm{~m}^{3} \cdot \mathrm{hr}^{-1}$ (fan setting 2) and $243 \mathrm{~m}^{3} \cdot \mathrm{hr}^{-1}$ (fan setting 3 ). Figure $8 \mathrm{~b}$ shows that as the dehumidifier air volumetric flow increases the change in absolute humidity of the air across the dehumidifier reduces from $0.005146 \mathrm{~kg}_{\mathrm{vapour}} / \mathrm{kg}_{\text {dryair }}$ at $124 \mathrm{~m}^{3} \cdot \mathrm{hr}^{-1}$ to $0.003594 \mathrm{~kg}_{\text {vapour }} / \mathrm{kg}_{\text {dryair }}$ at $243 \mathrm{~m}^{3} . \mathrm{hr}^{-1}$. As volumetric air flow increases a greater mass of air is passed through the dehumidifier and thus the capacity of the dehumidifier to reduce the air absolute humidity reduces. This relationship is in conflict with the moisture removal rate shown in Figure $8 a$. This is because moisture removal rate is a function of air mass flow rate. Figure $8 \mathrm{c}$ shows that as the dehumidifier air volumetric flow increases the latent (dehumidifier) effectiveness reduces from $68.52 \%$ at $124 \mathrm{~m}^{3} . \mathrm{hr}^{-}$ ${ }^{1}$ to $37.35 \%$ at $243 \mathrm{~m}^{3} \cdot \mathrm{hr}^{-1}$. Figure $8 \mathrm{~d}$ shows the dehumidifier cooling output increases as the volumetric air flow increases from a minimum of $613 \mathrm{~W}$ at $124 \mathrm{~m}^{3} \cdot \mathrm{hr}^{-1}$ to $1065 \mathrm{~W}$ at $243 \mathrm{~m}^{3} \cdot \mathrm{hr}^{-1}$. This is primarily due to a larger volume of air being conditioned. 

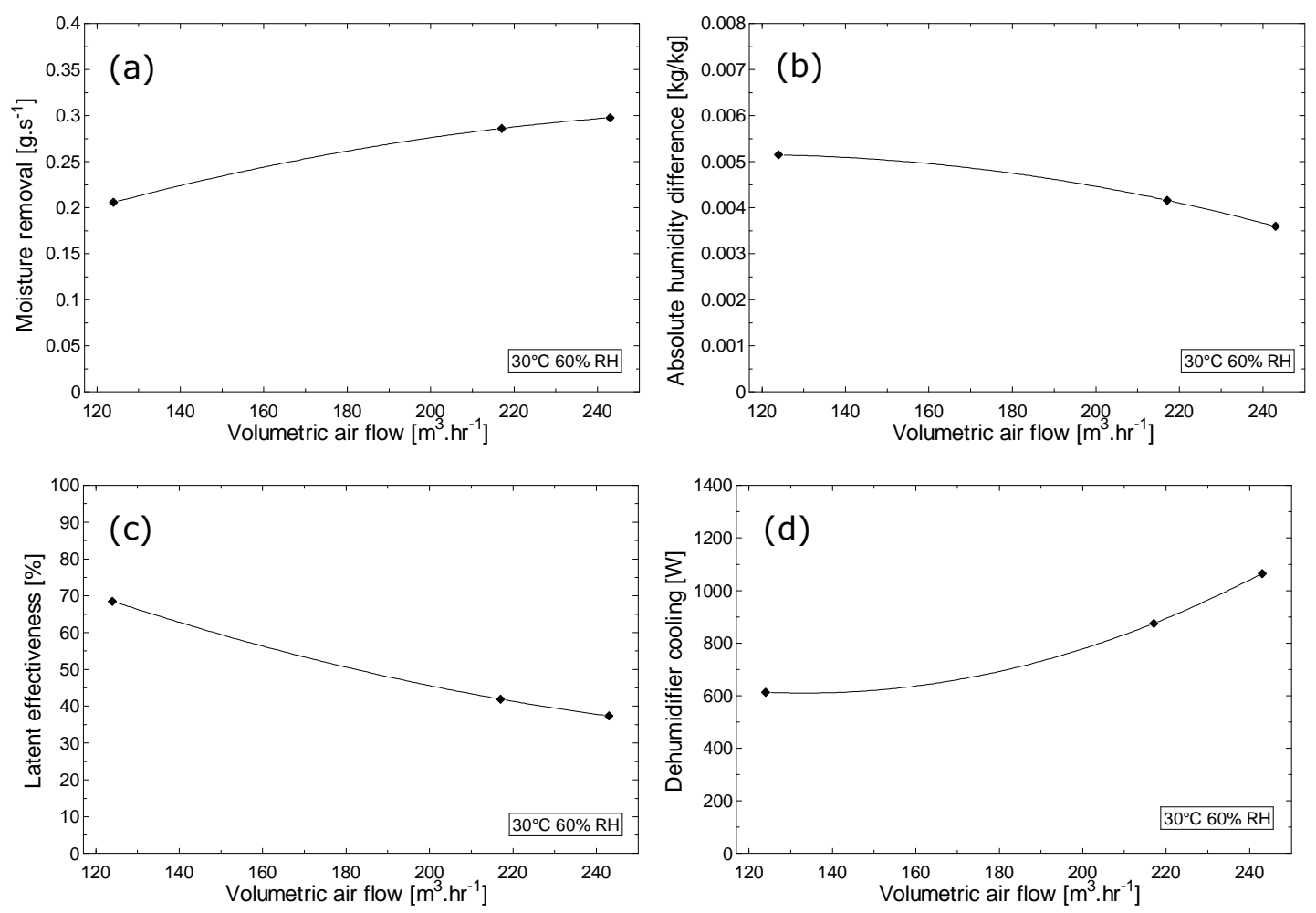

578

579

580

581 The selection of an appropriate volumetric air flow in the dehumidifier is dependent upon

582

583

584

585

586

587

588

589

590

591

592

593

594

595

596

597

598

Figure 8 (a) to (d) IDCS dehumidifier performance with inlet air volumetric flow the application and the desired supply air condition. Across all dehumidifier tests the maximum calculated relative uncertainties in the dehumidifier MRR, $\Delta \omega, \eta_{\llcorner}$and $\dot{Q}_{\text {cooling }}$ were $\pm 15.98 \%, \pm 15.1 \%, \pm 12.47 \%$, and $\pm 15.04 \%$ respectively.

\subsubsection{IDCS dehumidifier component analysis conclusions}

Over the investigated environmental conditions the dehumidifier performs well with a $\mathrm{CHKO}_{2}$ solution at a $0.65-0.7$ solution mass concentration. Dehumidifier moisture removal rates and cooling output increase with inlet air temperature and relative humidity in the range of 0.1541 to $0.4682 \mathrm{~g}^{-\mathrm{s}^{-1}}$ and $570 \mathrm{~W}$ to $1362 \mathrm{~W}$ respectively. The dehumidifier effectiveness values range from 30 - 47\%, typical of a membrane based HMX. Volumetric air flow has little impact on moisture removal but a marked impact on absolute humidity difference across the dehumidifier, latent effectiveness and dehumidifier cooling output. The evaporative inter-cooler provides between 400 and $800 \mathrm{~W}$ of cooling to the dehumidifier. The performance of the evaporative-inter cooler performance is strongly linked to the inlet air absolute humidity. Thus, in a building application it is beneficial to operate the evaporative inter-cooler on drier return room air. 


\subsection{IDCS regenerator component analysis}

600 The aim of the regeneration process is to remove the water vapour gained by the desiccant solution during the dehumidification process. The moisture removal rate from the dehumidifier air stream to the desiccant solution should equal the moisture addition rate from the desiccant solution to the regeneration air stream and thus the complete system can run continuously. During regenerator evaluation a water flow temperature of $60^{\circ} \mathrm{C}$ and water volumetric flow in the heating circuit of $2 \mathrm{~L} \cdot \mathrm{min}^{-1}$ was used. The IDCS regenerator component evaluation has assessed the impact of inlet air absolute humidity, volumetric air flow and volumetric water flow in the heating circuit on regenerator performance. Table 5 presents the results for six sample regenerator tests (same sample as dehumidifier), along with their associated absolute uncertainty.

610

611 Figure 9a shows the impact inlet air absolute humidity to the regenerator has on 612 moisture addition rate. The inlet air temperature to the regenerator ranges from 22 $61326^{\circ} \mathrm{C}$ and the absolute humidity ranges from 0.00708 to $0.01197 \mathrm{~kg}_{\text {vapour }} / \mathrm{kg}_{\text {dryair }}$. The 614 moisture addition rate ranges from a minimum of $0.07715 \mathrm{~g} \cdot \mathrm{s}^{-1}$ to a maximum of $6150.2229 \mathrm{~g} \cdot \mathrm{s}^{-1}$. Mass transfer is driven by a vapour pressure difference between the 616 desiccant solution and the regenerator airstream. As the absolute humidity of the regenerator inlet airstream increases so does its vapour pressure, resulting in a smaller moisture addition rate.

619
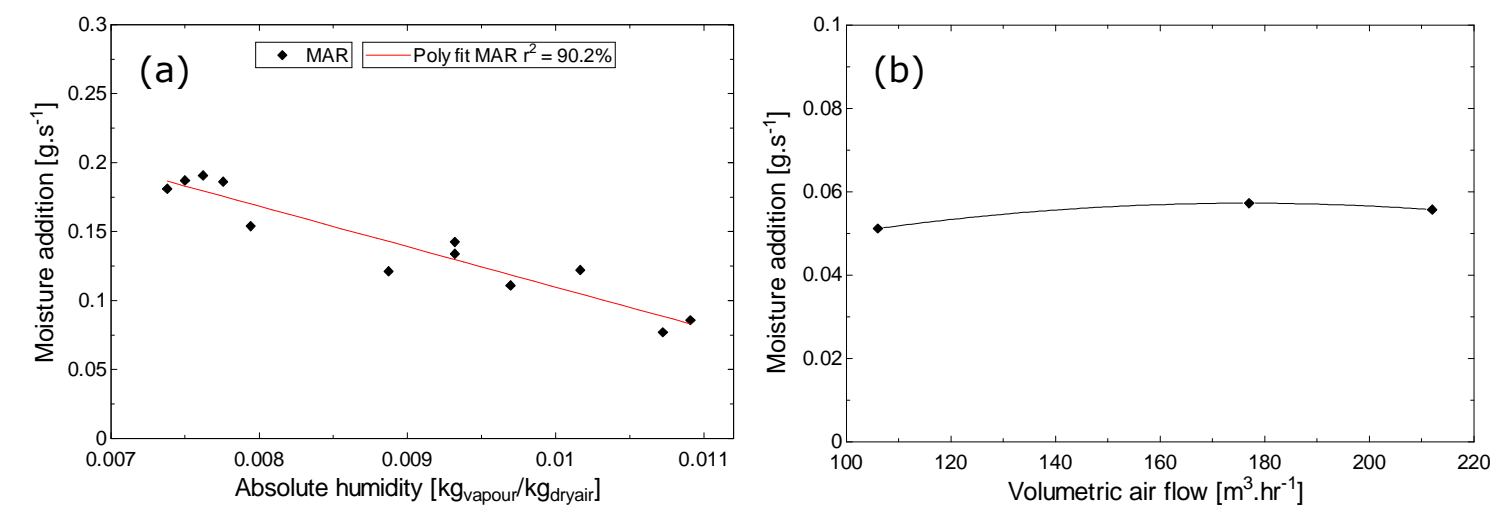
volumetric air flow

624 Figure 9b shows the variation of moisture addition rate from the desiccant solution to the 625 regenerator airstream as a function of regenerator volumetric air flow. The novel IDCS 626 integrates three components; regenerator, dehumidifier and evaporative inter-cooler into 627 one HMX core. As a result, the operation of each component has an impact on the 628 others. During volumetric air flow evaluation, the regenerator was operated 
629 independently i.e. no dehumidifier or evaporative cooler and as a result the regenerator

630 volumetric air flow shown in Figure $9 \mathrm{~b}$ is lower than that observed during simultaneous

631 dehumidifier and regenerator operation. The regenerator volumetric air flow rate is 632 increased from $106 \mathrm{~m}^{3} \cdot \mathrm{hr}^{-1}$ to $212 \mathrm{~m}^{3} \cdot \mathrm{hr}^{-1}$. It is evident that the volumetric air flow has 633 little impact on the moisture addition rate, with values ranging between 0.05118 to $6340.05727 \mathrm{~g} . \mathrm{s}^{-1}$, an increase of $0.00609 \mathrm{~g} . \mathrm{s}^{-1}$.

635

636 Figure 10a shows the variation of the moisture addition rate in the regenerator with 637 respect to the volumetric water flow in the regenerator hot water heating circuit over a $6381.5-6.5 \mathrm{~L} \cdot \mathrm{min}^{-1}$ range. It is evident that the volumetric flow of the water has a marginal 639 impact on regenerator capacity, with the moisture addition rate ranging from $0.2363 \mathrm{~g} . \mathrm{s}^{-1}$ 640 to $0.2619 \mathrm{~g} . \mathrm{s}^{-1}$, a difference of $0.0256 \mathrm{~g} . \mathrm{s}^{-1}$

641

642

643

644

645

646 Figure $10 \mathrm{~b}$ shows the regenerator thermal input as a function of volumetric water flow in 647 the regenerator liquid to air heat exchanger. The volumetric water flow has a large 648 impact on the thermal input to the system. At $1.5 \mathrm{~L} \cdot \mathrm{min}^{-1}$ the thermal input is $903 \mathrm{~W}$ at $6496.5 \mathrm{~L} \cdot \mathrm{min}^{-1}$ the thermal input is $1285 \mathrm{~W}$. As highlighted in Figure 10a the volumetric water 650 flow has little impact on the moisture addition rate in the regenerator, it is therefore 651 652 653 654 655 656

Figure 10 (a) to (b) IDCS regenerator performance with heat exchanger volumetric water flow optimal to operate the IDCS at a $1.5 \mathrm{~L} . \mathrm{min}^{-1}$ volumetric water flow in the regenerator hot water circuit., having a lower regenerator thermal input but a similar moisture addition rate will assist in improving the $\mathrm{COP}_{\text {th }}$ of the IDCS. This is discussed in more detail in Section 3.3. Across all regenerator tests the maximum calculated relative uncertainty in the regenerator MAR was $\pm 25.6 \%$.
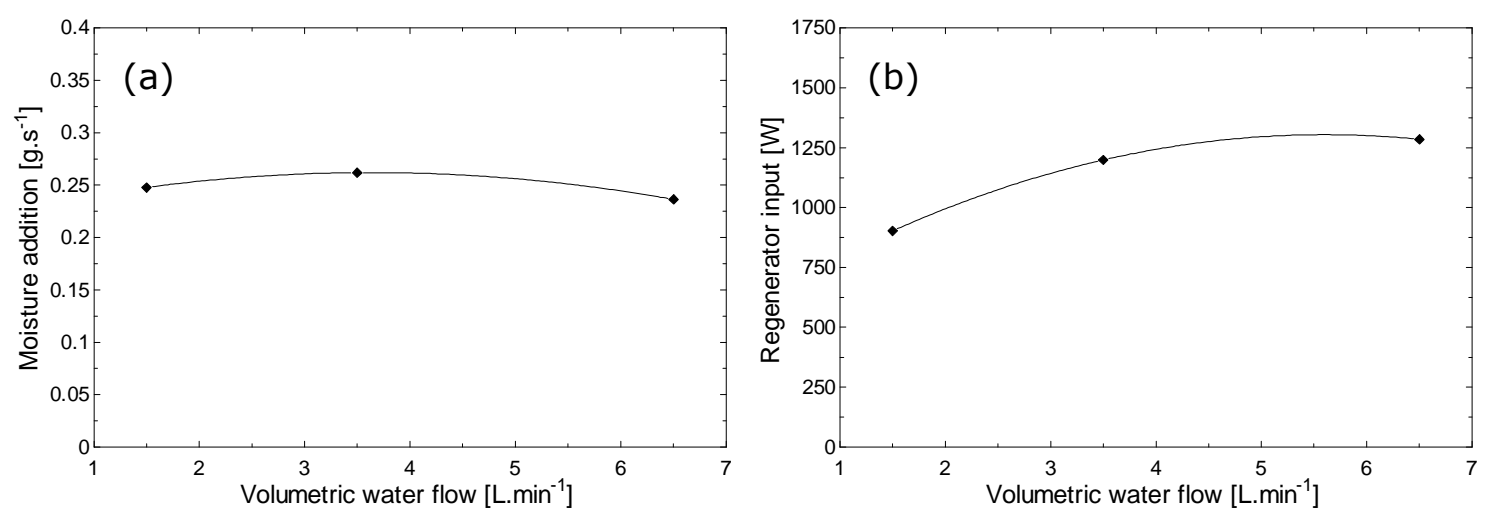


\subsubsection{IDCS regenerator component analysis conclusions}

658

659

660

661

662

663

664

665

666

667

668

669

670

671

672

673

674

675

676

677

678

679

680

681

682

683

684

685

686

687

688

689

690

Regeneration capacity increases with a lower inlet air absolute humidity. As a result it is recommended to operate the regenerator on drier return room air in a building application. Volumetric air flow and volumetric water flow in the heating circuit has marginal impact on regenerator capacity in the IDCS design. However, the volumetric water flow does influence the regenerator thermal input and should be minimised. It is evident, across the conditions investigated that there is an issue of instantaneous mass balance between the dehumidifier and regenerator i.e. the mass of water vapour removed from the air in the dehumidifier does not equal the mass removed from the desiccant solution in the regenerator. As a result, the complete IDCS cannot run continuously because the solution will become weak over time. The mass imbalance issue is discussed in more detail in section 3.3.

\subsection{Complete IDCS performance analysis}

The performance of the IDCS is evaluated with respect to its $\mathrm{COP}_{\mathrm{th}}$ and $\mathrm{COP}_{\mathrm{el}}$. The COP calculations are previously defined in Equations 10 and 11 respectively. An issue encountered with the IDCS is that an instantaneous mass balance between the dehumidifier and regenerator is not easily achievable. Mass imbalance is primarily due to the available surface area for heat and mass exchange in the regenerator being too small and an insufficient vapour pressure differential between the air and desiccant solution.

In order to regenerate the desiccant solution back to its original condition following the dehumidification process, the regenerator needs to operate for extended time periods. As a result, a theoretical adjusted thermal $\mathrm{COP}\left(\mathrm{COP}_{\mathrm{th}, \mathrm{adj}}\right)$ has been proposed in Equation 12. The $\mathrm{COP}_{\mathrm{th}, \mathrm{adj}}$ is a steady state value that takes into account the requirement of extended regenerator operation in order to achieve a system mass balance.

$$
\mathrm{COP}_{\text {th,adj }}=\frac{\dot{Q}_{\text {cooling }}}{\left(\frac{\mathrm{MRR}}{\mathrm{MAR}}\right) \dot{Q}_{\mathrm{reg}}}
$$

Figure 11a shows the average $\mathrm{COP}_{\text {th, adj }}$ and $\mathrm{COP}_{\mathrm{el}}$ for 21 IDCS tests. The black horizontal lines at $y=1$ and $y=2$ mark the benchmark values for $\mathrm{COP}_{\text {th }}$ and $\mathrm{COP}_{\mathrm{el}}$ respectively. The $\mathrm{COP}_{\mathrm{th}, \mathrm{adj}}$ values range from a minimum of 0.34 to a maximum of 1.26 , with an average of 0.72 . A COP th above 1.0 is comparable with 5.0 for a VCS driven by grid electricity, 
691

692

693

694

695

696

697

698

699

700

701

702

703

704

705

706

707

708

709

710

711

712

713

714

715

716

717

718

719

\section{7}

demonstrating the potential for highly efficient air conditioning with the IDCS design. Furthermore, the $\mathrm{COP}_{\mathrm{th}, \text { adj }}$ values are competitive with current VAS but at a smaller cooling capacity. The $\mathrm{COP}_{\mathrm{el}}$ values range from a minimum of 1.38 to a maximum of 3.67 , with an average of 2.5 . Figure $11 \mathrm{~b}$ demonstrates the psychrometric process of the complete IDCS, indicating the air state points in the dehumidifier, regenerator and evaporative inter-cooler. The data points in Figure $11 \mathrm{~b}$ are taken from test seven in Figure 11a. Table 6 presents the results for six sample system tests (same sample as dehumidifier and regenerator), along with their associated absolute uncertainty.
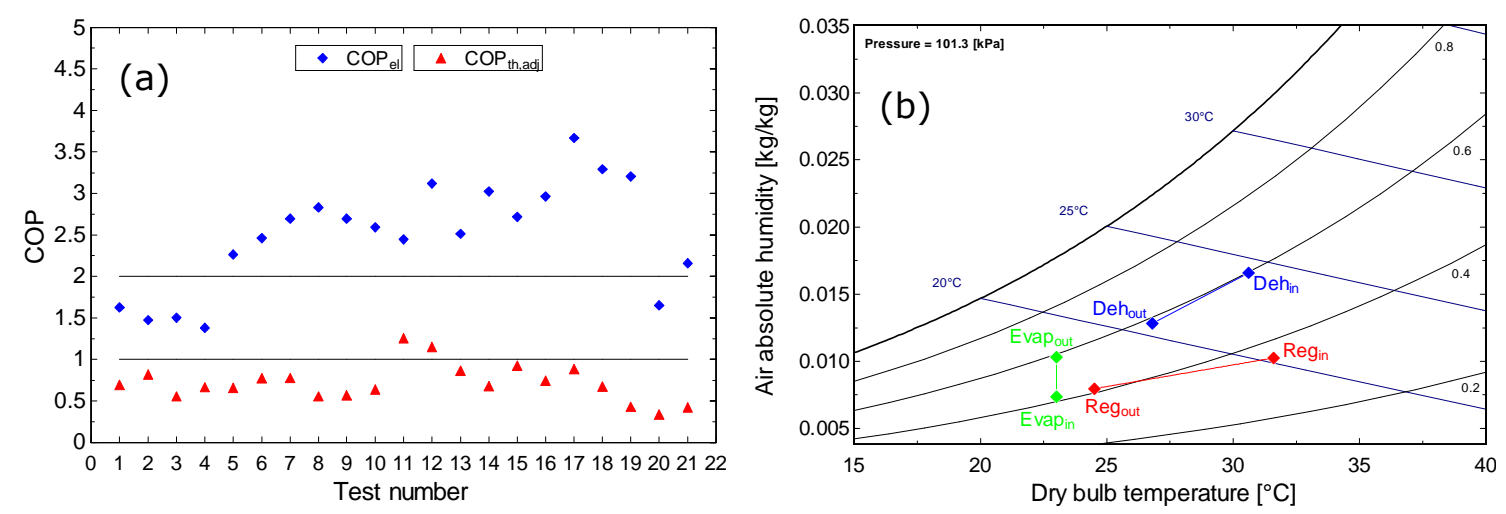

Figure 11 (a) Complete IDCS performance, and (b) IDCS psychrometric process

As the moisture addition rate in the regenerator increases, the $\mathrm{COP}_{\mathrm{th}, \text { adj }}$ increases. This is due to an improved mass balance between the dehumidification and regeneration processes, leading to a lower adjusted regenerator thermal input. The two $\mathrm{COP}_{\text {th, adj }}$ values greater than 1.0 are attained when the moisture addition rate in the regenerator is greater than $0.17 \mathrm{~g} . \mathrm{s}^{-1}$, which is achieved when the absolute humidity of the inlet air to the regenerator is less than $0.008 \mathrm{~kg}_{\text {vapour }} / \mathrm{kg}_{\text {dryair }}$. Thus, it can be concluded that the IDCS performs best when moisture addition in the regenerator is maximised, which occurs at a lower regenerator inlet air absolute humidity value. As a result, when operating the regenerator on fresh outside air liquid desiccant system performance will be poorer in hot and high humid climates. It is therefore favourable to operate the regenerator on drier return room air in such a scenario. The reasonable $\mathrm{COP}_{\mathrm{th}, \text { adj }}$ values demonstrate the potential of the IDCS design in building applications. Across all IDCS tests the maximum calculated relative uncertainties in the IDCS $\mathrm{COP}_{\text {th, adj }}$ and $\mathrm{COP}_{\mathrm{el}}$ were $\pm 27.73 \%$ and $\pm 15.93 \%$ respectively. 


\begin{tabular}{|c|c|c|c|c|c|c|c|c|c|}
\hline $\begin{array}{l}\text { Sample } \\
\text { number }\end{array}$ & $\mathbf{T}_{\mathrm{a}, \mathrm{in}, \mathrm{deh}}\left({ }^{\circ} \mathrm{C}\right)$ & $\mathbf{R H}_{\mathrm{a}, \mathrm{in}, \mathrm{deh}}(\%)$ & $\mathbf{X}_{\text {sol }}$ & $\mathbf{T}_{\text {sol,deh }}\left({ }^{\circ} \mathrm{C}\right)$ & $\operatorname{MRR}\left(g . \mathbf{s}^{-1}\right)$ & $\Delta \omega(\mathbf{k g} / \mathbf{k g})$ & $n_{L}(\%)$ & $\mathbf{Q}_{\text {cooling }}(\mathbf{W})$ & $\mathbf{T}_{\mathrm{a}, \text { out,deh }}\left({ }^{\circ} \mathbf{C}\right)$ \\
\hline 1 & $30.19 \pm 0.2$ & $51.37 \pm 1.7$ & 0.66 & $25.25 \pm 0.5$ & $0.15 \pm 0.052$ & $0.0019 \pm 0.00065$ & $30.02 \pm 8.50$ & $580 \pm 143$ & $27.77 \pm 0.2$ \\
\hline 2 & $30.71 \pm 0.2$ & $60.43 \pm 1.7$ & 0.66 & $25.39 \pm 0.5$ & $0.28 \pm 0.054$ & $0.0036 \pm 0.00068$ & $38.06 \pm 5.73$ & $994 \pm 153$ & $27.23 \pm 0.2$ \\
\hline 3 & $30.14 \pm 0.2$ & $70.72 \pm 1.7$ & 0.67 & $25.08 \pm 0.5$ & $0.42 \pm 0.060$ & $0.0055 \pm 0.00073$ & $45.36 \pm 4.85$ & $1045 \pm 162$ & $30.61 \pm 0.2$ \\
\hline 4 & $36.18 \pm 0.2$ & $50.08 \pm 1.7$ & 0.66 & $27.68 \pm 0.5$ & $0.26 \pm 0.067$ & $0.0034 \pm 0.00086$ & $32.27 \pm 6.57$ & $1177 \pm 188$ & $29.79 \pm 0.2$ \\
\hline 5 & $35.39 \pm 0.2$ & $60.33 \pm 1.7$ & 0.67 & $25.71 \pm 0.5$ & $0.36 \pm 0.070$ & $0.0047 \pm 0.00089$ & $31.91 \pm 4.97$ & $1201 \pm 193$ & $31.79 \pm 0.2$ \\
\hline 6 & $34.70 \pm 0.2$ & $70.56 \pm 1.7$ & 0.67 & $25.78 \pm 0.5$ & $0.45 \pm 0.073$ & $0.0060 \pm 0.00091$ & $34.14 \pm 4.26$ & $1318 \pm 198$ & $32.77 \pm 0.2$ \\
\hline
\end{tabular}

Table 5 Samples of regenerator performance data and associated uncertainty

\begin{tabular}{cccc}
\hline $\begin{array}{c}\text { Sample } \\
\text { number }\end{array}$ & $\mathbf{T}_{\mathbf{a}, \text { in,reg }}\left({ }^{\circ} \mathbf{C}\right)$ & $\mathbf{R H}_{\mathbf{a}, \text { in,reg }}(\%)$ & MAR $\left(\mathbf{g . \mathbf { s } ^ { - 1 }}\right)$ \\
\hline 1 & $25.80 \pm 0.2$ & $47.75 \pm 1.7$ & $0.11 \pm 0.057$ \\
2 & $23.49 \pm 0.2$ & $44.09 \pm 1.7$ & $0.14 \pm 0.049$ \\
3 & $25.49 \pm 0.2$ & $37.95 \pm 1.7$ & $0.19 \pm 0.056$ \\
4 & $23.96 \pm 0.2$ & $38.95 \pm 1.7$ & $0.20 \pm 0.052$ \\
5 & $25.23 \pm 0.2$ & $44.33 \pm 1.7$ & $0.18 \pm 0.055$ \\
6 & $24.09 \pm 0.2$ & $62.74 \pm 1.7$ & $0.12 \pm 0.056$ \\
\hline
\end{tabular}

723

Table 6 Samples of total system performance data and associated uncertainty

\begin{tabular}{ccc}
\hline $\begin{array}{c}\text { Sample } \\
\text { number }\end{array}$ & COP $_{\text {th, adj }}$ & COP $_{\text {el }}$ \\
\hline 1 & $0.58 \pm 0.30$ & $1.48 \pm 0.36$ \\
2 & $0.69 \pm 0.25$ & $2.49 \pm 0.38$ \\
3 & $0.53 \pm 0.16$ & $2.62 \pm 0.40$ \\
4 & $1.19 \pm 0.33$ & $3.01 \pm 0.48$ \\
5 & $0.76 \pm 0.24$ & $2.99 \pm 0.48$ \\
6 & $0.41 \pm 0.19$ & $3.28 \pm 0.49$ \\
\hline
\end{tabular}




\section{Conclusions}

728 To date, the application of liquid desiccant air conditioning in smaller (domestic) built

729

730

731

732

733

734

735

736

737

738

739

740

741

742

743

744

745

746

747

748

749

750

751

752

753

754

755

756

757

758

759

760 environment applications has been limited. This is primarily due to large system size and complexity, issues of desiccant solution leakage and carry-over and equipment corrosion. As a result, a novel IDCS has been developed with the aim of overcoming these barriers and facilitating the wider use of the technology in building applications. The IDCS combines the regenerator, dehumidifier and evaporative inter-cooler into a single HMX. The IDCS design reduces overall system size and limits the amount of piping, heat exchangers and pumps. A semi permeable micro-porous membrane is used to prevent desiccant solution entrainment in the supply air stream.

The paper has presented an evaluation, based on experimental data, of the novel IDCS operating with an environmentally friendly $\mathrm{CHKO}_{2}$ desiccant working fluid. Over the investigated environmental and operating conditions the dehumidifier performs well with the $\mathrm{CHKO}_{2}$ solution. Dehumidification capacity increases with inlet air temperature, relative humidity and air volumetric flow. However, a significant conclusion from the work presented is that an instantaneous mass balance between the dehumidifier and regenerator is challenging under most conditions. Across the variables investigated there is a greater instantaneous moisture removal rate in the dehumidifier than moisture addition rate in the regenerator. As a result, a theoretical adjusted thermal COP $\left(\mathrm{COP}_{\mathrm{th}, \mathrm{adj}}\right)$ has been presented which takes into account the requirement of extended regenerator operation in order to achieve a mass balance. The IDCS performs best when moisture addition in the regenerator is maximised, which occurs at a lower regenerator inlet air absolute humidity value. Across all tests performed an average $\mathrm{COP}_{\text {th,adj }}$ of 0.72 has been achieved.

This paper has demonstrated that the novel IDCS design and operating concept is viable. No previous work has been found in the literature regarding such an integrated design and thus the work provides progress to the field of liquid desiccant air conditioning technology for building applications. Future work should focus on increasing the regenerator to dehumidifier HMX surface area ratio and improving heat transfer rates to the regenerator air stream to improve system mass balance. 


\section{Nomenclature}

$762 \mathrm{CaCl}_{2}=$ Calcium Chloride

$763 \mathrm{CHKO}_{2}=$ Potassium Formate

$764 \mathrm{COP}_{\mathrm{el}}=$ electrical coefficient of performance

$765 \mathrm{COP}_{\mathrm{th}}=$ thermal coefficient of performance

$766 \mathrm{COP}_{\mathrm{th}, \mathrm{adj}}=$ adjusted thermal coefficient of performance

$767 \quad c_{p}=$ specific heat capacity $\left(\mathrm{J} . \mathrm{kg}^{-1} \cdot \mathrm{K}\right)$

$768 h=$ specific enthalpy of air $\left(\mathrm{J}^{\mathrm{kg}} \mathrm{kg}^{-1}\right)$

769 HVAC = heating, ventilation and air conditioning

770 IDCS $=$ integrated desiccant air conditioning system

$771 \mathrm{LiBr}=$ Lithium Bromide

$772 \mathrm{LiCl}=$ Lithium Chloride

$773 \dot{m}=$ mass flow rate $\left(\mathrm{kg} \cdot \mathrm{s}^{-1}\right)$

774 MAR $=$ moisture addition rate in the regenerator $\left(\mathrm{g} \cdot \mathrm{s}^{-1}\right)$

775 MRR $=$ moisture removal rate in the dehumidifier $\left(\mathrm{g} \cdot \mathrm{s}^{-1}\right)$

$776 \mathrm{p}_{\mathrm{atm}}=$ atmospheric pressure $(101325 \mathrm{~Pa})$

$777 \quad p_{\text {sol }}=$ vapour pressure of desiccant solution $(\mathrm{Pa})$

$778 \dot{Q}_{\text {cooling }}=$ dehumidifier cooling output (W)

$779 \dot{Q}_{\text {evap }}=$ evaporative cooler output (W)

$780 \dot{Q}_{\text {reg }}=$ regenerator thermal input (W)

$781 \mathrm{RH}=$ relative humidity $(\%)$

$782 T=$ temperature $\left({ }^{\circ} \mathrm{C}\right)$

$783 u=\operatorname{velocity}\left(\mathrm{m} . \mathrm{s}^{-1}\right)$

$784 \quad v=$ volumetric flow $\left(\right.$ L. $\left.\mathrm{min}^{-1}\right)$

$785 \quad V^{\prime}=$ volume $\left(\mathrm{m}^{3}\right)$

786 VAS = vapour absorption system

787 VCS = vapour compression system

$788 \dot{W}_{a u x, d e s}=$ IDCS electrical requirement $(\mathrm{W})$

$789 X_{\text {sol }}=$ desiccant solution mass concentration

790 
$\mathrm{a}=\mathrm{air}$

794

w = water

795

sol $=$ desiccant solution

796

in $=$ inlet

797

out $=$ outlet

798

eq $=$ equilibrium

799

800

\section{Greek letters}

801

$\eta_{\mathrm{L}}=$ latent (dehumidifier) effectiveness (\%)

802

$\rho=\operatorname{density}\left(\mathrm{kg} \cdot \mathrm{m}^{-3}\right)$

803

$\omega=$ air absolute humidity $\left(\mathrm{kg}_{\text {vapour }} / \mathrm{kg}_{\text {dryair }}\right)$

804

805

\section{Acknowledgements}

806

The authors would like to acknowledge the support from European Commission under

807 the Fuel Cell and Hydrogen Joint Undertaking Initiative ( $\mathrm{FCH}-\mathrm{JU}$ ) for the "Durable low

808 temperature solid oxide fuel cell Tri-generation system for low carbon buildings" project,

809 agreement No. 303454. The authors would also like to thank the EPSRC and CDT in

810 Hydrogen, Fuel cells and their Applications for their continued financial and academic

811 support.

812

\section{References}

814 [1] Pérez-Lombard, L., J. Ortiz, and C. Pout, $A$ review on buildings energy consumption information. Energy and Buildings, 2008. 40(3): p. 394-398.

[2] Smith, S.T., V.I. Hanby, and C. Harpham, A probabilistic analysis of the future potential of evaporative cooling systems in a temperate climate. Energy and Buildings, 2011. 43(2-3): p. 507-516.

[3] Welch, T., CIBSE Knowledge Series: KS13 - Refrigeration, H. Carwarardine and K. Butcher, Editors. 2008, CIBSE Publications.

[4] Ouazia, B., H. Barhoun, K. Haddad, M. Armstrong, R.G. Marchand, and F. Szadkowski. Desiccant-evaporative cooling system for residential buildings. in 12th Canadian Conference on Building Science and Technology. 2009. Montréal, Québec: Institute for research in construction.

[5] Zhang, L.Z., Energy performance of independent air dehumidification systems with energy recovery measures. Energy, 2006. 31(8-9): p. 1228-1242.

[6] Srikhirin, P., S. Aphornratana, and S. Chungpaibulpatana, A review of absorption refrigeration technologies. Renewable and Sustainable Energy Reviews, 2001. 5(4): p. 343-372. 
830

831

832

833

834

835

836

837

838

839

840

841

842

843

844

845

846

847

848

849

850

851

852

853

854

855

856

857

858

859

860

861

862

863

864

865

866

867

868

869

870

871

872

873

874

875

876

877

878

879

[7] Duan, Z., Zhan, Changhong., Zhang, Xingxing., Mustafa, Mahmud., Zhao, Xudong., Alimohammadisagvand, Behrang., Hasan, Ala, Indirect evaporative cooling: Past, present and future potentials. Renewable and Sustainable Energy Reviews, 2012. 16(9): p. 6823-6850.

[8] Pietruschka, D., U. Eicker, M. Huber, and J. Schumacher, Experimental performance analysis and modelling of liquid desiccant cooling systems for air conditioning in residential buildings. International Journal of Refrigeration, 2006. 29(1): p. 110-124.

[9] Jain, S. and P.K. Bansal, Performance analysis of liquid desiccant dehumidification systems. International Journal of Refrigeration, 2007. 30(5): p. 861-872.

[10] Lowenstein, A., Review of Liquid Desiccant Technology for HVAC Applications. American Society of Heating, Refrigerating and Air-Conditioning Engineers, 2008. 14(6).

[11] Longo, G.A., Gasparella, A., Experimental and theoretical analysis of heat and mass transfer in a packed column dehumidifier/regenerator with liquid desiccant. International Journal of Heat and Mass Transfer, 2005. 48(25-26): p. 52405254.

[12] Kozubal, W., J. Woods, J. Burch, A. Boranian, and T. Merrigan Desiccant Enhanced Evaporative Air-Conditioning (DEVap): Evaluation of a New Concept in Ultra Efficient Air Conditioning. 2011.

[13] Hassan, H.Z. and A.A. Mohamad, A review on solar cold production through absorption technology. Renewable and Sustainable Energy Reviews, 2012. 16(7): p. 5331-5348.

[14] Halliday, S.P., C.B. Beggs, and P.A. Sleigh, The use of solar desiccant cooling in the UK: a feasibility study. Applied Thermal Engineering, 2002. 22(12): p. 13271338.

[15] Gommed, K. and G. Grossman, Experimental investigation of a liquid desiccant system for solar cooling and dehumidification. Solar Energy, 2007. 81(1): p. 131138.

[16] Fong, K.F., Chow, T. T., Lee, C. K., Lin, Z., Chan, L. S., Comparative study of different solar cooling systems for buildings in subtropical city. Solar Energy, 2010. 84(2): p. 227-244.

[17] Beccali, M., P. Finocchiaro, and B. Nocke, Energy performance evaluation of a demo solar desiccant cooling system with heat recovery for the regeneration of the adsorption material. Renewable Energy, 2012. 44(0): p. 40-52.

[18] Jain, S., S. Tripathi, and R.S. Das, Experimental performance of a liquid desiccant dehumidification system under tropical climates. Energy Conversion and Management, 2011. 52(6): p. 2461-2466.

[19] Liu, S., A Novel Heat Recovery/Desiccant Cooling System, in Architecture and Built Environment. 2008, The University of Nottingham: Nottingham.

[20] Melinder, A., Thermophysical Properties of Aqueous Solutions Used as Secondary Working Fluids, in Energy Technology. 2007, KTH Energy and Environmental Technology: Stockholm.

[21] Taylor, J.R., An Introduction to Error Analysis: The Study of Uncertainties in Physical Measurements. Second Edition ed. 1997, Sausalito, California: University Science Books.

[22] James, S., A New Working Fluid 'Potassium Formate' for use in Absorption Heat Pumps, in Architecture and Built Environment. 1998, The University of Nottingham: Nottingham. 